\title{
Los de afuera no son de palo. Notas reflexivas sobre una investigación de amor en varones gais
}

The others matter. Reflexive notes on a research about love among gay men

Maximiliano Marentes

Instituto de Investigaciones Gino Germanim

Facultad de Ciencias Sociales de la Universidad de Buenos Aires,

CONICET, Argentina

maximiliano.marentes@hotmail.com

\section{Resumen:}

En el presente trabajo propongo un ejercicio de reflexividad metodológica sobre las categorías con las que fui comparado en mi investigación sobre amor en varones gais. El objetivo es reconocer que dichas categorías no son arbitrarias sino que adquieren un sentido particular en la conformación de parejas, entendidas estas como una red que se ensambla por más de dos personas. Así, ser comparado con un levante, un tercero en discordia, un terapeuta y un amigo lleva a dinamizar el lugar de investigador, al tiempo que aporta información sobre el amor gay realmente existente.

Palabras Clave: Amor, Gay, Reflexividad, Pareja.

\section{Abstract:}

In this paper I propose an exercise of methodological reflexivity on the categories to which I was compared in my research about love among gay men. The aim is to recognize that those categories are not arbitraries but get particular sense in the conformation of couples. I understood the couples as a network assembled for more than two individuals. So, being compared to a guy trying to date, a third party, a therapist and a friend makes the researcher role more dynamic, at the same time that provides information about really existing gay love.

KEYworDs: Love, Gay, Reflexivity, Couple.

\section{INTRODUCCIÓN: ¿QUIÉN SOY YO PARA QUE ME CUENTEN ESO?}

Me propongo, en este trabajo, realizar un ejercicio de reflexividad acerca de mi lugar como investigador en mi proyecto doctoral que busca describir historias de amor de varones gais. El objetivo de estas páginas es reconstruir las categorías con las que por momentos me comparan mis entrevistados a la hora de pensarme, intentando demostrar que esas categorías no son arbitrarias, sino que se inscriben dentro de la compleja trama de relaciones sociales de la que formamos parte con mis sujetos de investigación. La apuesta radica en recuperar un esquema que toma a las relaciones de pareja como una red de la que forman parte no solo los, por ejemplo, novios, sino también amigos, familiares, terapeutas y terceros en discordia.

Entre octubre de 2017 y noviembre de 2018 realicé el trabajo de campo de mi investigación doctoral. Esta consiste en describir - desde la perspectiva pragmática de Bazin (2017) - las historias de amor de varones gais jóvenes que viven en la Ciudad de Buenos Aires y el Gran Buenos Aires, ${ }^{1}$ con el fin de comprender el modo en que aman. Para lograr eso, en más de un encuentro entrevisto a cada uno de estos treinta varones. Además de su lugar de residencia, el otro criterio de inclusión es que tengan entre veinte y cuarenta años; es decir, que hayan sido socializados bajo el régimen de la "gaycidad" 2 (Meccia, 2011). En el primer encuentro charlamos un poco sobre su historia de vida,referida a su lugar de nacimiento, escolarización, trayectoria laboral, familia y salida del clóset. En el segundo encuentro nos concentramos en sus historias amorosas,

Recepción: 07 de diciembre de 2018 - Aprobación: 03 de octubre de 2019 - Publicación: 12 de diciembre de 2019 
de parejas y experiencias sexuales, aquellas que ellos consideran relevantes. ${ }^{3}$ Para nuestro tercer encuentro, ya nos enfocamos en momentos y cosas puntuales de cada una de las relaciones de pareja. Y en el último, el intento es recuperar cómo aparecen otras personas (familiares, amistades, terceros en discordia) en esas historias de amor. Esto es en términos generales. Claro que con una duración promedio de una hora y media, en cada uno de estos encuentros hablamos de muchas cosas más. Además, como cada historia tiene sus ribetes y particularidades, las entrevistas son bastante diferentes entre sí. Por la complejidad y disparidad de las historias entre sí, incluso dentro de la trayectoria amorosa de un mismo entrevistado, las entrevistas, que parten de una serie de puntos que se busca abordar, nunca son realizadas del mismo modo. Es decir, aunque fueran entrevistas directivas, en el trabajo de campo devinieron entrevistas etnográficas (Guber, 2004, 2011), en las que tanto la observación de la situación de las entrevistas y sus respectivas notas de campo como la no direccionalidad del dispositivo adquirieron un lugar central.

A grandes rasgos, ese es mi trabajo de campo. Habiendo esbozado someramente el qué de mi investigación, es necesario que aclare del mismo modo el cómo. Desde la sociología se suele analizar el amor en su imbricación con la modernidad. En la medida en que el proyecto moderno occidental implicó la consolidación de la figura de individuo, en paralelo se constituyó la imagen de un sujeto que puede comenzar a formar uniones libremente, y, en última instancia, casarse por amor. De allí que la pregunta que resuena en muchos de esos trabajos (Beck y Beck-Gernsheim, 2001; García Andrade y Sabido Ramos, 2014; Giddens, 2004; Illouz, 2009, 2012; Jónasdóttir, 2014; Luhman, 2008) es sobre el amor, en su clave individual -a partir de la idea de que la individuación es un proceso sociológico-, en dos temporalidades diferentes: la modernidad y la modernidad tardía. En dichos trabajos, el amor suelte terminar quedando relegado a una dimensión relativamente escindida de la vida de las personas, pero, sobre todo, de la red de relaciones que sostienen a dichos individuos. Mi apuesta, en cambio, consiste en recuperar algunas de las críticas a la concepción individuocéntrica ${ }^{4}$ de la modernidad (Elias, 1996, 2008; Latour, 2007, 2008), ${ }^{5}$ para pensar que las parejas son siempre una red en la que dos suelen ser sus protagonistas, pero que son sostenidas por un entramado de otros sujetos que actúan en esa pareja. Mientras que para el saber popular "los de afuera son de palo", ${ }^{6}$ propongo a lo largo de estas páginas recuperar, a partir de cuatro anécdotas, cómo se desafía esa premisa cuando, en algunos momentos, aparezco formando parte de esa red.

Se podría objetar que las entrevistas son técnicas de investigación individualizantes, por lo que no sería la estrategia adecuada para un abordaje que se propone recuperar la red que compone las relaciones de pareja. Ciertamente que las entrevistas invitan a los participantes a narrar a partir de un punto de vista individual sus trayectorias afectivas, por lo que un ejercicio de observación participante puede ilustrar otros puntos de la conformación de esa red. A pesar de los límites del trabajo con base en entrevistas, su potencialidad radica en dos puntos, que abordajes alternativos podrían complementar. El primero de ellos recae en que el objetivo general de la investigación es reconstruir los sentidos que los actores dan a sus prácticas a partir de sus experiencias. Como se sostiene en otros trabajos (Marentes, 2017a, 2017b, 2019), esas experiencias se cristalizan en historias de amor, en las que se imprimen los sentidos del amor realmente existente. Apelo a esta fórmula para definir el análisis de amor en sus condiciones sociales de producción, a partir de aquellas experiencias que fueron significadas como amorosas, para no detenerme solo en la dimensión idealista del amor, es decir, en cómo debiera ser. El segundo punto radica en recordar que la apuesta es por comprender los entramados sociales -en que se incluyen otras personas y cosas en un sentido amplio- de los cuales se valen las personas para consolidarse como individuos. Es decir, siguiendo la propuesta de Araujo y Martucelli (2010), reconocer los modos en que los soportes de individualización permiten consolidar aquel proyecto inacabado que son los individuos modernos, cuya existencia la sociología del amor da por sentada. A partir de las historias que relatan los entrevistados se puede rastrear la presencia de otros actantes (Boltanski, 2000; Latour, 2008; Nardacchione, 2011) en dichas trayectorias. De todos modos, cabe alertar que trabajar con historias de amor heterogéneas -algunas siguen consolidándose, otras ya finalizaron y otras se van apagando 
de a poco- implica reconocer que no todas las categorías que componen este texto pueden emerger en el trabajo de campo.

Ya establecido el qué y el cómo, es necesario que explicite el con quién reflexiono sobre mi lugar como investigador en este trabajo de campo. En la introducción de Rosana Guber (2014) a un libro que reúne ejercicios de reflexividad de diferentes antropólogas de campo, luego de repasar diferentes acepciones sobre este término, sostiene que el interés de las autoras del libro es situar tanto el lugar de las condiciones de producción como los avatares en el campo, porque todo ello también forma parte de la realidad que se busca conocer. En estas páginas resuena el trabajo de Diego Zenobi (2010), que propone que las categorías con las que él fue tratado por familiares de víctimas de la tragedia de Cromañón ${ }^{7}$ durante su investigación permiten entender el entramado de relaciones de la que forman parte dichos familiares. Es decir, que tales categorías adquieren un sentido en dicha situación de conocimiento; poseen un sentido específico entre las personas a quienes se investiga. La reflexividad, como muestran los capítulos del libro compilado por Piovani y Muñiz Terra (2018), deviene cada vez más un imperativo en el trabajo de quienes hacemos investigación social.

Entonces, en este trabajo me propongo reflexionar con quiénes me comparan estos varones para contarme sus historias de amor. Estas comparaciones no implican que me sitúen de una vez y para siempre en dichas categorías. Por el contrario, propongo pensarlo como un constante movimiento de pivote, cuyo centro radica en la figura del investigador al que siempre vuelvo. Si bien me centro en mi relación con cuatro varones, eso estuvo presente en muchas otras entrevistas. A partir de un esquema que habilita a pensar a las parejas conformadas por más de dos personas, intento un ejercicio de reflexividad que permita no solo problematizar mi lugar como sujeto de la investigación, sino también detentar un lugar específico en algunas parejas. Por eso, comienzo con cómo fui visto por Juli.

\section{El CHAMUYo DE LA TESiS DE DOCTORAdo PARA LEVANTAR}

A Juli lo conocí por Twitter. De ese modo podría comenzar una historia de amor de aquellas que recabo -de hecho, alguna así lo hace-. Mi intento en este apartado no es solo explicar que en un primer momento fui pensando por Juli como alguien que quería "levantarlo", es decir, conquistarlo, sino también reflexionar sobre qué dice eso de las prácticas amorosas de los varones a quienes entrevisto.

La tarde del sábado 24 de marzo de 2018 estábamos en un café de Palermo ${ }^{8}$ Juli, dos amigos de él y yo. Era el primero de nuestros encuentros. Después de haber terminado con la primera parte de la entrevista propiamente dicha, grabada con su consentimiento, seguimos charlando de cosas muy variadas. Ya cuando hube apagado el grabador, Juli, este joven de casi veintitrés años, me confesó que me había stalkeado ${ }^{9}$ en Internet. Cuando vio que mi investigación sobre amor en varones gais era real, accedió a que nos encontráramos para que lo entrevistara. Había pensado, por un momento, que podría ser un viejo pedófilo que intentaba acosarlo, a lo que uno de sus amigos le dijo: "Bueno, tampoco pedófilo, sos mayor de edad". Juli, con el desparpajo que lo caracteriza al hablar, contó que había pensado que lo de la tesis de doctorado era el típico chamuyo ${ }^{10}$ para intentar levantarlo. Nos reímos por lo del "típico chamuyo", ya que tampoco es un recurso tan utilizado para conquistar chicos, pero que, si yo no estuviera de novio, podría llegar a usarlo.

Esta brevísima escena condensa todo, pero para entenderla en su profundidad, faltan algunos elementos adicionales. Primero, cómo lo contacté a él y no a otra persona. Entre quienes sigo en Twitter se encuentra Mauri, el novio de Juli. En alguno de sus tweets, en los que publica fotos de ellos dos juntos, dijo que vivía en la zona norte del conurbano bonaerense. Para marzo de 2018 me di cuenta de que la mayoría de los chicos que había entrevistado hasta ese momento vivían en Capital, y, por el mismo proyecto, había decidido incorporar varones que vivieran en provincia, es decir, en los alrededores de la Ciudad de Buenos Aires. Estaba buscando sumar varones del Gran Buenos Aires, ya tenía algunos contactos, pero ninguno hasta ese momento de zona norte. ${ }^{11}$ Decidí arriesgarme y enviarle un mensaje privado a Mauri para contarle de mi investigación y saber 
si podía entrevistarlo. Le gustó la idea, pero como tenía poco tiempo entre trabajo y estudio (un tema que, como me contó Juli después, le genera algunas molestias, pero que aguanta, es decir, tolera, porque es el último año de la carrera de ingeniería de Mauri) le resultaría imposible. Al preguntarle si conocía otros varones de zona norte para que entrevistara me dijo que Juli, su novio, que también vivía por allí, contaba con un poco más de tiempo.

Comencé entonces a seguirlo en Twitter y le mandé un mensaje directo (o $D M$ en la jerga de dicha red social). Para no quedar como un desubicado, le dije que su novio me sugirió que le escribiera y ahí charlamos sobre el porqué del contacto. Enseguida tuvo buena predisposición para que nos encontráramos. Su único problema era que los encuentros iban a poder ser los fines de semana, ya que en la semana terminaba muy tarde su trabajo como vendedor de autos en la concesionaria del padre y le resultaría muy complicado reunirse. Le conté que por mí eso no era un problema en absoluto y que también podríamos llegar a encontrarnos en un lugar que le quedara cómodo, ya que como becario doctoral tengo bastante flexibilidad horaria, y también laboral. Quedamos en encontrarnos el sábado 24 de marzo ${ }^{12}$ a las 15.30 horas cerca de Plaza Italia, ${ }^{13}$ en el barrio de Palermo. En esas charlas por $D M$ de Twitter me preguntó si se podía ir acompañado. Le dije que sí y que no había inconveniente alguno en que fuera con alguien, aun cuando para mí era un desafío, pues hasta entonces las entrevistas que venía realizando habían sido siempre sin la presencia de otras personas.

El viernes 23 de marzo le volví a escribir por Twitter para confirmar el encuentro del día siguiente. Lo hice a riesgo de parecer insistente, pero me generaba incertidumbre no tener otro medio de comunicación con él que no fuera Twitter. Aunque ya le había pasado mi número de celular para que charláramos por WhatsApp, él no me había escrito por ese medio. El mismo sábado, media hora antes de que nos encontráramos, Juli me avisó que estaba llegando en treinta minutos. Le avisé que llevaba una remera celeste, de modo que le resultara más fácil reconocerme. Cuando llegó, yo estaba en la esquina del café, nos saludamos y fuimos directo al interior del negocio.

Antes de comenzar con la grabación, le conté en qué consistía la investigación. Interrumpiéndome me preguntó si yo era homosexual y si estaba en pareja. Al contestar afirmativamente a ambas preguntas, su cara se mostró distendida. Ser gay me sitúa en una cierta posición de privilegio, al mismo tiempo que de riesgo. Pues si bien compartimos ciertos códigos, los entrevistados nunca dejan de tener la idea de que un varón que intenta levantarlos, es decir, seducirlos. La manera que encontré para lidiar con ello es informar que estoy de novio. ${ }^{14}$ Tras unos minutos de entrevista, llegó su primer amigo y, tiempo después, el otro. Cuando finalizamos con la grabación, nos integramos en la charla con sus amigos, que ocupaban la otra mitad de la mesa en que nos encontrábamos los cuatro, y nos quedamos en el mismo lugar un prolongado período de tiempo conversando sobre muchas cosas, entre ellas, que me había stalkeado. Nos despedimos al rato y quedamos en que la próxima vez podríamos llegar a encontrarnos por zona norte, incluso en Nordelta, ${ }^{15}$ que quedaba cerca de su casa y que además era un lugar al que yo nunca había ido hasta entonces. Cuando iba a tomar el colectivo para regresar a mi casa, una pregunta rondaba mi cabeza: ¿qué le hizo pensar a Juli que yo había intentado levantarlo?

Para abordar este interrogante es necesario valerse de la reflexividad en el trabajo de campo. Retomar una de sus acepciones, recuperada en Guber (2014), que se basa en la propuesta de Donna Haraway del conocimiento situado, me llevaría a pensarme como un cuerpo situado en una determinada condición de saber. Esta propuesta reflexiva está muy extendida en los estudios de género, en los que se suele leer una suerte de compendio de características que se supone, a veces a priori, nos permiten entender desde donde habla el sujeto de conocimiento. Si seguimos esta tradición, podría decir de mí mismo que soy un varón blanco (aunque tampoco tan blanco), ni gordo ni delgado (aunque con muchas disconformidades con mi cuerpo), gay (y no por eso tan disidente sexual), cis (es decir, no trans), con un nivel educativo alto (pero de un campo disciplinar bastante bastardeado por cierta lógica utilitarista), con un nivel socioeconómico relativamente bueno (aunque podría ser mejor), buen mozo (modestia aparte), que aparenta tener más de sus entonces veintisiete años (muy a mi pesar), y un sinfín de rasgos más que ayudarían a definirme. Si bien una descripción in extenso de todos estos criterios es necesaria en cualquier ejercicio de reflexividad, corre el riesgo de abonar 
una reflexividad narcisa (Guber, 2014), que solo termine hablando del sujeto de la investigación y no recupere el cómo este investigador es interpelado en el trabajo de campo.

En cambio, propongo recuperar otras claves reflexivas que me permitan entender que el cómo fui tratado por Juli aporta pistas fundamentales de aquello que estoy investigando: las relaciones amorosas en varones gais. Con esto no quiero decir que el haberme visto como alguien que lo quería levantar fuera algo exclusivo de la investigación con varones gais. De hecho, existe un vasto conocimiento, oficial pero sobre todo extraoficial, acerca de los intentos de avances entre informantes y quienes investigan. Como sostiene Guber (2014), el modo en que nos ven se relaciona con cómo entramos al campo. Para Juli, en un primer momento, fui solamente un usuario de Twitter que se contactó con él luego de que su novio le dijera que debía hacerlo. Como para él fui un anónimo durante unos días, tardó en pasarme su número de celular. De hecho, a la salida del café, me dijo que después me iba a escribir por WhatsApp, que no me había agregado hasta ese momento porque desconfiaba de mis motivos para contactarlo. Y esa desconfianza también lo llevó a que para el primer encuentro él fuera acompañado: como no estaba seguro de mis intenciones, tenía miedo de que fuera un cualquiera que quería quién sabe qué cosa (aunque, a decir verdad, él pensó que lo había intentado levantar). Bromeó, incluso, con que de haber sido un levante, ni loco habría invitado a sus amigos a ese primer encuentro. Podría, entonces, pensarse cómo Juli incorporó a sus amigos a una situación de virtual levante como había pensado que podría haber sido-, como testigos, otra forma de participación de otras personas en las relaciones amorosas.

De todos modos, no queda claro aún por qué me situó en la lógica del levante. Es necesario, por lo tanto, reconocer que el medio virtual es cada vez más una de las formas que tienen las personas para conocerse, pero sobre todo para intentar establecer un intercambio erótico-afectivo (Illouz, 2010, 2012). Esta práctica se encuentra bastante extendida en el caso de varones gais, como han demostrado algunos trabajos (Boy, 2008; Leal Guerrero, 2011; Marentes, 2017c). De hecho, Leal Guerrero explica que conoció a sus informantes cuando él ingresaba a ciertas páginas de contacto, justamente para buscar la aphrodisia o el ejercicio del erotismo (Leal Guerrero, 2011). De allí que no era descabellado que Juli pensara que le había escrito para levantarlo. Muchos de los varones que entrevisto conocieron a sus parejas por medios virtuales. Algunas veces se conocieron gracias a redes sociales como Facebook (ya que tenían amigos en común, entre los que había algunos gais), Instagram (que seguían a tal o cual usuario porque estaba bueno) ${ }^{16}$ o Twitter (donde las publicaciones les resultaban divertidas). Otras veces lo hicieron por medio de sitios de contacto como algunos chats (hace algunos años), páginas de citas como OkCupid (en la que se establecen porcentajes de compatibilidad de perfiles) o páginas de contacto como ManHunt (exclusivamente para varones que buscan tener algo sexual con otros varones). Y en un sinfín de oportunidades estos varones se conocieron a partir de aplicaciones para celulares que utilizan tecnología de geolocalización (Happn, Tinder y sobre todo Grindr). Juli, que conoció a Mauri por Grindr - una app o aplicación para celular mayormente utilizada por gais-, tuvo un par de malas experiencias con esta herramienta. Algunos conocidos de él le han comentado que había gente en Grindr que utilizaba su foto en un perfil que no era el de él.

Como sostiene Zenobi (2010), las categorías con que nos piensan nuestros interlocutores nos dice mucho de ese entramado de relaciones que estamos investigando. Y, de hecho, esto cobra total sentido cuando a Juli yo le parecí un intento de levante virtual, que utilizó un chamuyo un poco raro, pero que no por eso dejaba de generarle desconfianza. ¿Por qué? Básicamente porque si bien entrar en contacto con gente por medios virtuales es una actividad cada vez más recurrente en nuestras sociedades, no deja de generar un momento de incertidumbre y ansiedad, que incluso puede llevar a experimentar decepciones (Illouz, 2012), más si se tienen en cuenta las malas experiencias que había tenido Juli por gente que utilizaba sus fotos en perfiles falsos.

Luego de reflexionar en este apartado sobre cómo hubiera podido insertarme en el campo, visto a priori como alguien más que se acerca por medios virtuales para intentar levantar gente con una excusa poco habitual, es necesario retomar un cabo suelto. A Juli le cambió la cara cuando le dije que tenía novio, se sintió más relajado. Y no solo él quedó tranquilo con eso, sino también su novio, con quien tenía una relación 
abierta. ${ }^{17}$ Cuando Juli le contó que nos íbamos a ver un par de veces más, Mauri le dijo que yo quería levantarlo y le preguntó si era lindo. Juli dijo que no estaba mal; es decir, no era feo, pero que ya estaba de novio. Para Mauri, que tuviera novio, implicaba que no iba a intentar conquistar a su novio. Para otro novio, en cambio, me convertí en un tema de celos.

\section{Tercero EN Discordia ENVUELto EN ESCENA DE CELOS}

Ya a la cuarta semana de habernos visto por primera vez, con Patricio estábamos en el último encuentro de nuestras entrevistas semanales. Las cuatro veces nos vimos en el mismo local de una cadena de cafés, en el centro porteño, cerca de su trabajo como cocinero en un hotel. Mientras yo terminaba de tomar un té, él iba comiendo el sándwich que había pedido, pues no había tenido tiempo de almorzar en su horario laboral. Este varón gay, de veintinueve años, a quien había conocido por una amiga en comn, prefería que le fuera haciendo preguntas concretas, así le era más fácil hablar.

$\mathrm{Al}$ charlar sobre secretos, aparecieron los celos y me dijo que la última escena era muy, muy reciente: el domingo anterior a nuestro encuentro. Me dispuse a preguntar por qué había sido, pues me interesaba saber quién más podría haber estado merodeando esta pareja monógama que ya llevaba más de cinco años; su respuesta me sorprendió. Cuando le dijo a Lean, su novio, que se vería por última vez conmigo ese martes de marzo, medio en chiste, medio en serio, le hizo una escena de celos. Patricio continuó hablando, minimizando la situación, ya que no era algo tan en serio ni tan trascedente. ¿De qué manera llego a entretejerme en esta red como un tercero en discordia? Aún más, ¿̇tercero como quién?, es decir, ¿en comparación con qué otros pude ser caracterizado? Para entenderlo, es necesario que exploremos otras cuestiones previas.

Como mencioné en la introducción, en el cuarto de los encuentros pregunto por esas otras personas que forman parte de las parejas. Con Patricio, ya que hacía bastante tiempo que estaba de novio con la misma persona, era una tarea sencilla, pues no debíamos ir y venir entre tantas relaciones como sí sucedió con otros entrevistados. Lean había sido su único novio oficial, de quien se había enamorado y con quien proyectaba viajes y hasta vivir juntos. Más adelante en la entrevista, le pregunté por cómo se llevaban sus familiares (su papá, su mamá, su hermana y su abuela) con Lean, y también cómo se llevaba él con su suegro, su suegra y su cuñado. Después continuamos con sus amigos y amigas, siempre en procura de recuperar anécdotas puntuales con la intención de que eso dejara ver cómo se había ido ensamblando esta pareja. Finalmente, quienes suelen completar el cuadro de personas que aparecen en las relaciones son los exnovios, chongos ${ }^{18}$ y levantes de cada uno de los miembros de la pareja, así como terceros en discordia.

En el caso de Patricio, había reaparecido hacía muy poco tiempo su primer amor, o sea, el primer chico con quien estuvo, que había conocido por algún chat. Él vivía en otra ciudad de la provincia de Buenos Aires, por lo que las veces que se vieron durante esos dos meses que duró su relación fue en casa de Patricio, que -como seguía viviendo con los papás- lo presentaba como un amigo. Resulta que este chico, a quien el Patricio de hoy no considera como un exnovio, hacía un tiempito le había enviado una solicitud de amistad por Facebook. Él la aceptó y luego se lo contó a Lean. Con el estilo directo que lo caracteriza al hablar, Patricio se lo comentó del mismo modo que podría haberle dicho que había vendido algunos mates de su emprendimiento. Su novio se quejó un poco, pues le parecía bastante raro que después de tanto tiempo -más de siete años-él lo agregara y Patricio lo aceptara. Se lo hizo saber. Al poco tiempo, Patricio se dio cuenta de que no tenía mucho sentido tenerlo de amigo en Facebook y terminó eliminándolo.

Pero no es que Lean podría haber arrojado la primera piedra; Patricio no olvidaba que, hacía mucho tiempo -es cierto-, una noche Lean se había quedado a dormir en la casa de un amigo. Claro, un amigo que casualmente también era gay. Al día siguiente, ya en su casa, Lean le pidió por favor a Patricio que lo perdonara por lo que había hecho. Sin entender demasiado, le preguntó qué le pasaba. Lean le dijo que fuera a su casa así podrían charlar. En su habitación - porque Lean también vive con sus padres- ${ }^{19}$ conversaron 
de la noche anterior. Lean y su amigo durmieron cada uno en una cama individual, en la misma habitación. El amigo intentó que pasara algo, pero solo consiguió acariciarle la cabeza a Lean. Él, ya con una caricia se sintió muy mal; su cabeza fue invadida no solo por una mano sino también por un "No puedo hacerle esto a Patricio". De hecho, no había pasado nada más. ¿Tanto por una caricia? Pues sí. A Lean le había gustado durante mucho tiempo su amigo, pero eso ya había quedado en el pasado. Patricio lo perdonó y comprendió que no era para tanto.

Ahora, ¿̇se puede ser amigo de alguien con quien hay un interés erótico? Es relativamente habitual entre varones gais tener amigos (también gais) con quienes las relaciones comenzaron a partir de un interés erótico. A veces en los vínculos gais el sexo es la vía de entrada. Hakim (2012) habla de capital erótico para hacer referencia a aquellos atributos de los sujetos que los vuelven más deseables, no solo en el mercado de intercambios eróticos, sino también que pueden ser traducidos en capitales dentro de otros campos. En muchos trabajos sobre varones gais se destaca cómo el interés inicial en el sexo derivó en la sociabilidad (Boy, 2008; Leal Guerrero, 2011; Meccia, 2006, 2011; Sívori, 2004). En las entrevistas, a veces el sexo es la vía de entrada para el amor o para formar una pareja. Pero también a veces el amigarche ${ }^{20}$ es un contacto por medio del cual se consigue trabajo. Sugiero al pasar, ya que no es el eje del trabajo, el capital sexual como uno de los capitales que se juegan en el campo de las relaciones gais y que puede ser transformado en otros beneficios. Con todo, lo que esta digresión pretende ilustrar es que la distinción entre amigos, terceros en discordia, levantes, chongos -al menos entre varones gais- puede llegar a ser un poco más porosa de lo que se podría pensar, o al menos ser más contextual que sustancial.

Volvamos a Patricio y a mí como factor de una escena de celos. Un ex que aparece después de más de un lustro y un amigo de Lean, con el que había pasado algo pero que ya había prescrito, son personas que se insertan en la trama narrativa de esta historia de amor con, justamente, eso: historia. Cuando repasamos la forma en que aparecieron ex y terceros en discordia en su relación con Lean, era esperable que fueran recuperadas estas personas, de las que ya me había hablado Patricio. Lo que sí no me había imaginado es que aparecieran en nuestra charla los celos de su novio. Tras haber tragado un mordisco del sándwich y beber un poco de agua con gas, Patricio me dijo que el domingo anterior, de hecho, cuando le contó a Lean que me vería nuevamente, él había armado - un poco en tono de broma, un poco en serio- una escena de celos.

Ya la primera vez que Patricio le contó que nos íbamos a juntar para nuestro primer encuentro, Lean jugó el papel de novio celoso. Le preguntó para qué quería entrevistarlo a él. Patricio le contestó que era porque estaba haciendo mi tesis de doctorado sobre amor en varones gais. “Ah, o sea que también es gay”, objetó Lean. Patricio le dijo que no sabía, pues hasta ese momento no nos conocíamos, pero que era amigo de Andrea, una amiga de Patricio a quien Lean conocía y con quien se llevaban muy bien. Desde esa vez, la cosa no pasó a mayores, hasta esta última vez, en la que Lean le planteó cómo podía ser que nos hubiéramos visto tantas veces en un par de semanas, y que seguramente yo tenía otras intenciones, que quería levantarlo.

A medida que me contaba esto, yo sonreía. Claro, podría ser por narcisismo, pero también porque es lo que me sale cuando me pongo nervioso. Seguramente Patricio se dio cuenta de mi cara de nerviosismo y mi risa comprometida, que terminó diciendo que no había pasado nada grave en realidad, que esa "escenita" de celos formaba parte de un juego, de uno de esos modos lúdicos que tienen con Lean para reírse de las cosas que les pasan habitualmente. Ya más calmo, luego de un sorbo de té, le pregunté si se había generado una discusión por eso. Patricio me dijo que no, que no había motivo por el cual discutir y que Lean se olvidaba rápido de las cosas. De hecho, fue Patricio quien le recordó que ya le había hecho una escena de celos la vez que le contó que nos veríamos por primera vez. "Es así, medio cuelgue", ${ }^{21}$ sintetiza Patricio.

El “cuelgue” de Lean amenizó una situación que podría haber generado algún tipo de conflicto. Pero hay dos componentes más que sirven para entender cómo se diluyó rápido esa escena. El primero se relaciona con esas otras personas que forman parte de la pareja. Si recuperamos la noción de actantes, que retoma la sociología pragmática francesa (Boltanski, 2000; Latour, 2008; Nardacchione, 2011) de la lingüística funcionalista, otras personas están (estamos) involucradas en las relaciones de pareja de alguna manera. Yo, 
un varón gay que investiga amor en varones gais y entrevista a su novio, fui visto por Lean como un tercero en discordia. Pero hubo otra actante que me tendió una mano y me sacó de ese brete: Andrea. Esa amiga en común que teníamos con Patricio, y que además era muy amiga de Lean, era mi salvoconducto. No podía ser que ella le presentara alguien a Patricio que pudiera hacer peligrar su relación con Lean, relación que ella bendice con su amistad.

Un segundo componente que distendió una escena de celos fue el directo, concreto y pragmático modo de hablar de Patricio. Esta manera de decir las cosas fue alguna vez un motivo de queja de Lean, pues acusaba a su novio de ser poco expresivo, casi como una muestra de desinterés para entablar una comunicación con él. Un día estaban en la casa de Patricio y Lean esbozó esa queja en voz alta. La hermana de Patricio al escuchar el reclamo comenzó a reír. Y, en tanto que otro actante, le comentó a su cuñado que él siempre había sido así. Ella contó que cuando Patricio era muy pequeño y volvía de jardín, a la expectante pregunta sobre cómo le había ido, escuetamente respondía: "Bien.Jugué", pues ya no tenía más nada para agregar. El modo directo de hablar de Patricio, reconocido por su hermana como una de sus características, terminó quitándole importancia y entidad a una microescena de celos, que, en última instancia, no tenía tanta relevancia.

Hasta ahora vimos cómo fui visto como intento de levante para Juli y como foco de celos para el novio de Patricio. La diferencia entre una y otra categoría podría ser pensada en relación a la idea de las dos caras de una misma moneda. Es decir, mientras que en el primero de los casos fui pensado por el mismo entrevistado como alguien con interés de seducirlo, en el segundo quien pensó en eso fue el novio del entrevistado. De allí que aunque mi participación fue similar, aparecí en esas relaciones de manera diferente. Para Juli, como un varón que intentaba conquistarlo, por lo tanto, un potencial levante; para Patricio, en cambio, un investigador que hizo que su novio le hiciera una escena de celos. Cabe preguntarse si ese virtual tercero en discordia, como fui pensado por Lean, se debe a que la relación entre ellos es monógama y a que hace muchos años que están de novios. Esa podría ser una explicación, aunque es cierto que para otros varones que venían tejiendo una relación hacía muy poco tiempo, sus partenaires me vieron como una amenaza, aun cuando su acuerdo era no monógamo.

Pero las categorías con las que fui pensado no se agotan en el intento de levante y de un tercero en discordia. Mencioné que Patricio prefería que le hiciera preguntas concretas en vez de que le dijera algo así como: "Contame tu historia de amor". Ese dato anecdótico pasaría desapercibido de no ser por la relación que había tenido este joven con la psicoterapia. Se atendió un tiempo con una psicóloga que lo ayudó con un tema puntual, pero que no le gustó que lo tratara como un paciente de segunda, ${ }^{22}$ ya que iba por obra social y no se atendía de manera particular. Para él, por el momento, ya había sido suficiente esa experiencia. Para otros, en cambio, más acostumbrados a ese dispositivo de salud, tendieron a compararme con eso, con un terapeuta.

\section{Que QUEDE ACÁ: LA ENTREVISTA COMO SESIÓN}

Con Marcos tuvimos mucha afinidad desde el principio. Nos conocíamos por una amiga en común, ya nos habíamos visto un par de veces y después de las entrevistas comenzamos a desarrollar una amistad. Entrevistar a Marcos es sentarse a escucharlo, porque apenas le decía "Contame tal cosa", comenzaba a hacer una gran descripción con lujo de detalles de todo. El primer encuentro lo tuvimos un jueves, día que él estuvo libre, porque se había pedido el día en su trabajo en un organismo del Estado para preparar unos trabajos finales de la maestría en Ciencias Sociales que estaba cursando. Cuando estaba en camino me mandó un mensaje de WhatsApp diciéndome que si llegaba y él no estaba, era porque se había ido a pasear al perro. Pero antes de que llegara, ellos dos ya habían regresado. Marcos había dispuesto el mate y un budín, que había comprado en una dietética, en la mesa que preparó en el amplio balcón.

En el primer encuentro me suelo concentrar en la historia de vida, como dije en la introducción, intento recuperar trayectorias educativas, laborales y datos sobre familia, entre otros. Al ser una entrevista con preguntas abiertas y no una encuesta, puede que, a veces -como en el caso de Marcos-, la entrevista alcance las 
dos horas sin que hasta ese momento hubiésemos hablado sobre la salida del closet. Antes de continuar con el detalle del encuentro con Marcos, cabe aclarar por qué me concentro en todos aquellos otros aspectos que a priori no se relacionan con las historias de amor que intento describir. Justamente esa había sido mi primera impresión. Pensé: "Relevo los datos sociodemográficos a modo de encuesta y me concentro en el amor". Pero a medida que avanzaba el trabajo de campo, me daba cuenta de que el amor era cada vez menos una dimensión extramundana de la vida de las personas. Se me fue haciendo más y más necesario conocer un poco algunos acontecimientos trascendentes en las trayectorias de estos varones, para recuperar los modos en que, como en el caso de Marcos, el amor, el estudio, el trabajo, la familia, y todo eso que mi mente pensaba separado, estaba mucho más entremezclado. Él consiguió su actual trabajo gracias a formar parte de una agrupación política de diversidad sexual. Este hecho sirvió para que su novio ingresara en la misma dependencia estatal, lo que les permitió juntar dinero para mudarse juntos. Por eso, creo que para el estudio del amor (aunque puede llegar a aplicar a otros temas) es necesario abrirse a otras cosas que las mentes racionales modernas separan, y que, de no acercarnos a las historias en toda su densidad - parafraseando a Los Piojos-, "desde lejos no se ven”. ${ }^{23}$ De allí que deba matizarse el carácter autorreferencial del amor, que señalan, de distinta manera, Illouz (2012) y Luhmann (2008).

De regreso a Marcos, la charla fue muy, muy amena, o al menos eso sentí viendo que él podía ir explayándose. Cuando le pregunté por el colegio al que había ido, me habló de un colegio parroquial -de relativo buen nivel educativo- que tenía una cuota muy accesible para una típica familia de clase media que hacia fines de los años noventa hacía malabares para no caerse. Del colegio fuimos y vinimos: para atrás, para adelante, para los amigos, para la familia, para el cura, a quien a los quince años -muy angustiado- le contó que tenía dudas sobre su sexualidad. Este tipo de charlas en las que se reflexiona sobre la propia vida implican conectar con cosas que ya llevaban un tiempo sin revisarse. La charla lo enfrentaba con recuerdos que debían volver a hilarse para que esa narrativa adquiriese sentido.

A los doce días nos volvimos a ver, nuevamente en la casa de su padre, donde residía momentáneamente por los arreglos que estaba haciendo en la suya -también propiedad del padre-. Le pregunté cómo se había sentido la vez anterior, si había estado cómodo y si se había quedado pensando en algo -preguntas que suelo hacer en cada encuentro y que a veces sirven para volver a hablar de temas que quedaron pendientes o que no fueron lo suficientemente desarrollados-. Marcos me respondió que se había sentido bien, pero que le había resultado raro tener la sensación de estar, no en una entrevista sociológica (género que conoce por profesión), sino en una sesión de psicoterapia. De hecho, se lo había contado a su psicóloga, cuando la vio en los días que mediaron entre nuestra primera y nuestra segunda "sesión". ${ }^{24}$ Le dijo que se quedara tranquila, que no la iba a abandonar y bromeó con que mal no le vendría ahorrarse unos pesos.

¿Por qué a Marcos yo le había recordado a un terapeuta? ¿Qué quería decir que nuestros encuentros pudieran pensarse como sesiones de consulta psicológica? Para responder estos interrogantes debemos contemplar otras cuestiones. En primer lugar, el género discursivo entrevista sociológica. La situación de entrevista puede ser pensada, si seguimos a Bajtin (1982), como un género discursivo específico. Es decir, como un conjunto de enunciados relativamente estables de las diferentes esferas de la praxis social. Según este autor, se entiende que los sujetos no son libres a la hora de disponer del sistema de signos (la lengua) para hablar, sino que están condicionados por restricciones discursivas que dependen tanto del campo discursivo en el que se encuentran como de su posición social. Estas restricciones se dan en tres niveles: estilístico (repertorio de opciones léxicas y sintácticas), estructural (cómo se organiza el texto) y temático (sobre qué se habla). In abstracto, la entrevista suele ser un espacio discursivo en el que alguien le hace preguntas a otra persona. En su rol de interrogador, quien pregunta suele hacerlo con la intención de recabar información pero tratando de no direccionar las respuestas (nunca está de más aclarar que esto sería en términos ideales).

Esta digresión sobre géneros discursivos es necesaria, ya que muchas veces se los ha analizado a partir de su carácter concluso, relegando a un segundo plano la estabilidad relativa de los enunciados. Si bien esos análisis han servido para entender mejor las configuraciones discursivas, lo han hecho a riesgo de tomar a los 
géneros discursivos como compartimentos estancos y ya cerrados que contienen un conjunto delimitado de enunciados. Adam y Heidmann (2004) proponen en cambio la noción de efectos de genericidad. Los autores consideran a la genericidad como la puesta en relación de un texto con categorías genéricas abiertas, por lo que sería una necesidad sociocognitiva la que liga todo texto al interdiscurso de una formación social. Los efectos de genericidad remiten a rasgos específicos del texto para que, al momento de ser leído, pueda ser inscrito en un género discursivo en particular. En los momentos en que esos enunciados conectan con otros discursos, emerge la confusión genérica. Volviendo al caso de Marcos, ¿qué fue lo que lo hizo pensar que nuestra entrevista sociológica se parecía a una sesión de psicoterapia? La respuesta debe contemplar tanto el estilo como el tema. Con respecto al primero, es cierto que juego bastante al terapeuta en las entrevistas. Es decir, trato de intervenir lo menos posible con el fin de escuchar qué es lo que tienen para decirme mis entrevistados, sin intentar completar la frase o adelantarme a sus respuestas, respuestas que puedo llegar a intuir pero que en última instancia desconozco.

De todos modos, fundamentalmente lo que confunde las entrevistas con una terapia suele ser el tema. Si bien con Marcos hasta ese primer encuentro no habíamos hablado tanto del amor, mi carta de presentación había sido la investigación sobre "amor gay". Como sucede en las sociedades occidentales modernas, en la medida en que el amor es visto como una dimensión individual de la vida de las personas (Giddens, 2004; Illouz, 2009, 2010, 2012), los problemas que este causa se enfrentan con herramientas también individualizantes. Y en eso las terapias psicológicas juegan un rol fundamental. De allí que es bastante habitual que las entrevistas puedan ser comparadas con sesiones. Ahora bien, visto que la psicoterapia no es la única herramienta individualizante con la que cuentan las personas, ¿por qué es tan común este desplazamiento genérico? Justamente porque estamos en Buenos Aires.

Es de conocimiento popular que las terapias psicológicas están muy extendidas en Buenos Aires. Aún más, se sabe que existe una fuerte tradición psicoanalítica en Argentina. Que se tomen las entrevistas como una sesión no solo indica que esta práctica está extendida en la sociedad en su conjunto, sino que está bien representada entre los varones con los que trabajo. ${ }^{25}$ En ese primer encuentro había decidido preguntar si hacían o habían hecho psicoterapia en algún momento, y la amplia mayoría contestó afirmativamente. Posiblemente, quien venga leyendo esto infiera: "la psicoterapia está extendida entre los entrevistados, pero por ser más o menos jóvenes profesionales de una clase media”. ${ }^{26}$ Aquí es necesario detenerse un momento en la dimensión de clase.

Muchos de estos varones gais tienen ocupaciones, niveles educativos, consumos y estilos de vida actuales que tenderíamos a caracterizarlos como de clase media (Adamovsky, Visacovsky y Vargas, 2014). Pero algo que permite hacer un trabajo que se detenga someramente en las historias de vida y en las familias es reconstruir sus trayectorias y, por ejemplo, el nivel educativo de sus padres. Por ello pude conocer que varios de estos varones son hijos de empleadas domésticas -ocupación de mujeres de sectores bajos-, que otros han vivido en villas, y que su posición actual no se condice con esas trayectorias. La clase social no fue un criterio a priori para definir los varones a entrevistar, aunque sí lo tomo en cuenta al momento del análisis. De todos modos, es necesario aclarar que el presente de clase no necesariamente se traduce linealmente con la trayectoria o los orígenes. Intento no tomar acríticamente a la clase social como una variable explicativa de lo social que determina el resto de los comportamientos, sino solo traerla a escena cuando lo hacen los entrevistados. Este criterio no influyó en la proyección de las categorías según las cuales fui pensado por mis entrevistados. Es cierto que algunos entrevistados tenían niveles socioeconómicos más altos que el mío y otros más bajos, pero durante el trabajo de campo no sentí que hubiera una proyección diferencial de las categorías con las que me pensaron que se explicara a partir de la pertenencia de clase. Me pregunto, ¿será acaso que la experiencia gay opera en trayectorias específicas como un canal de ascenso social (el cual resulta manifiesto cuando se comparan las situaciones actuales de los entrevistados con las de sus hermanos y hermanas heterosexuales) ${ }^{27}$ 
Ya sea por la imbricación de clase y la gaycidad o no, muchos hacen terapia y suelen verme momentáneamente a mí como un terapeuta. Pero que me vean de ese modo implica asimismo que me tengo que comportar como tal. Esto me lo hizo saber indirectamente Marcos, cuando luego de haberme contado muchas cosas íntimas, me advirtió que no estaba seguro de si quería que entrevistara a su novio, pues me había dicho cosas que aquel no debería saber. Las palabras de Marcos me hicieron replantear nuevamente el trabajo de campo que estaba comenzando a desarrollar. La primera vez fue cuando comenté ingenuamente delante de otra gente que con uno de los varones presentes iríamos luego a hacer la entrevista para mi trabajo de campo. Apenas estuvimos solos, él me pidió que no dijera que formaba parte del grupo de sujetos entrevistados. De ahí en más me llamé al silencio, hasta que otras veces eran los mismos entrevistados quienes les contaban a otras personas que estaban colaborando con mi investigación. ${ }^{28}$

A Marcos lo contacté apenas comenzaba a hacer entrevistas. En ese momento tenía pensado entrevistar a quince varones solteros y a quince que estuvieran en pareja, con la intención de entrevistar también a sus actuales parejas. Cuando le conté mi propósito a Marcos, él, después de terminada nuestra segunda sesión, manifestó sus dudas. Ahí me di cuenta de que haber sido comparado con un terapeuta implicaba mantener ciertos secretos para evitar que el otro me preguntara de qué había hablado con su novio. Fue en ese momento cuando decidí no insistir con entrevistar a los novios, a no ser que ellos quisieran y me lo pidieran. ¿Implica esto que no se pudieran entrevistar a los dos miembros de la pareja en una investigación? No necesariamente. En otras investigaciones (por ejemplo, Olcón-Kubicka, 2016), los miembros de la pareja fueron entrevistados por separado y por personas del mismo sexo. Esa alternativa podría haber sido una solución de haber contado con otros recursos -económicos y humanos- para llevar el trabajo de campo de manera conjunta. Con todo, como la unidad de análisis son las historias de amor de cada una de las personas, opté por entrevistar solo a un partenaire, a no ser que explícitamente me fuera dicho que su pareja quería ser entrevistada también como sucedió en dos ocasiones-. Con ellos, a su vez, reconstruimos sus historias amorosas, incluso las que trascienden su actual relación.

Para Marcos, a veces nuestros encuentros fueron una suerte de sesión, como las que tenía con su psicóloga, que le habían hecho entender que no tenía que desplazar su propia individualidad por causa de su novio. Palabras similares le decían sus amigas, a quienes les compartía esos problemas. Terapeutas y amistades sirven de confidentes. Analizaremos a partir de aquí de qué modo fui visto por los entrevistados como un confidente al que se le podían contar cosas que los amigos a veces no lograrían comprender.

\section{ESCUCHANDO SIN JUZGAR: CASI COMO UN AMIGO}

Ya era alrededor de las cinco de la madrugada de un frío domingo de marzo cuando con Luchi salimos del boliche. ${ }^{29}$ Todavía faltaba un rato para que la fiesta se apagara, pero además de que estábamos cansados, el grupo de amigos con el que habíamos salido a bailar ya se había ido por completo. Solo quedamos Luchi y yo. Estábamos por el barrio porteño de Palermo, a unas cuadras de su casa, por lo que él estaba muy contento de que no tenía que viajar para regresar a su hogar. Me preguntó cómo me volvería a mi casa y le dije que chequearía en Internet, pero que creía que tomaría un colectivo que estaba seguro pasaba por ahí cerca. Le pregunté si sabía dónde tomarlo.l, además de conocer la zona, tenía un sentido de la ubicación espacial más desarrollado que el mío. Sabía que la parada del colectivo estaba de camino a su casa por lo que se ofreció a acompañarme.

Llegamos a la esquina donde supuestamente estaba la parada del colectivo, el cual de noche tarda bastante en pasar. Según Luchi, ahí lo tomaba él a veces para ir al trabajo, una empresa multinacional de consultoría financiera. Le propuse que fuéramos a otra esquina, donde estaba seguro que pararía. Luchi, a pesar de ser más de la cinco de la madrugada, parecía no tener mucha premura por llegar a su casa. Obviamente fuimos charlando. Le conté que las empanadas que cenamos me habían caído mal, por lo que las había estado repitiendo toda la noche, incluso en el boliche. A él no le habían caído tampoco tan bien. De hecho, hacía 
ya un tiempo que no comía empanadas: desde que vivía solo. Luchi se había separado de su novio, con el que convivieron poco más de un año, a fines de agosto de 2017. Ya se sentía superbien y la angustia se le había ido pasando. Pero a veces sucedía que en determinadas ocasiones muy puntuales se daba cuenta de cómo ciertas costumbres todavía seguían ligadas al hecho de estar en pareja (y, por ende, a su ex). Una de ellas era comer esta comida típica en Argentina. Desde que se había separado no había vuelto a pedir empandas, pues en los lugares donde compraba solo le vendían a partir de media docena y él solo comía tres. Le dije que también podía comprar seis y comer tres, y dejar las restantes para otro día. Pensativo, pero poco convencido, me dijo que sí, mientras caminábamos a paso constante para contrarrestar el frío de esa temprana aparición del otoño.

Cuando llegamos a la otra parada, estábamos solamente nosotros dos esperando el colectivo. Después de un largo rato llegó otro chico que debía tomar el mismo transporte que yo. Cuando todavía estábamos solos en la parada, saqué el tema sobre cómo andaba de amores. Si bien se lo veía bien, no hacía mucho que se había separado. Le pregunté si sabía algo de su ex, a quien seguía teniéndole un enorme cariño y aprecio, a pesar de que la pareja ya se había terminado. Me contó que justamente lo había visto la noche anterior, que lo había visto muy bien y que se lo notaba contento. Luchi hizo un silencio, miró para abajo, luego a cada lado y después clavó la mirada en mí, que estaba parado muy cerca del cordón de brazos cruzados para darme calor. Se soltó y me dijo que me iba a decir algo que hasta ese momento no se lo había dicho a nadie, ni siquiera a sus más amigos, porque ellos no lo hubieran podido entender como sí podría hacerlo yo. Algo más había pasado con su ex...

Evidentemente para Luchi - por encontrarnos en el contexto de haber compartido conmigo una salida junto a un grupo de amigos-, yo podría haber sido asociado a la categoría amigo. Pero no solo eso, sino que podría parecer un amigo confiable, desprejuiciado, que podría llegar a entenderlo y no lo juzgaría. Además, de alguien que no lo iba a exponer delante de otros. ¿Qué había pasado para que yo llegara a ese lugar? ¿Qué cosas supe entender? ¿Qué cosas callar? Aún más, ¿cuál había sido el lugar de los amigos a lo largo de su relación con su ex? Empecemos por algunas cuestiones.

A Luchi lo conocí por un amigo en común. Cuando estaba empezando el trabajo de campo le pregunté si sabía de alguien a quien pudiera entrevistar y me pasó el número de este joven. Con él nos vimos tres veces en una cafetería de una cadena internacional por el barrio de Palermo. Para el cuarto encuentro fui a su casa, ya que como ese día tenía home office, iba a estar desde temprano en la comodidad de su hogar. Con Luchi la primera vez que nos vimos fue en la cafetería y enseguida fluyó muy bien la charla. En total fueron grabadas más de siete horas y media, además de todo el tiempo que charlamos off the record, ${ }^{30}$ tanto antes como después de las grabaciones. Por ese amigo en común, con Luchi nos vimos algunas veces más. Dos de ellas en bares, en eventos de nuestro amigo, con mucha más gente alrededor. Ya para ese entonces había aprendido que no tenía que decir a quién entrevistaba, pues después del anterior llamado de atención, estaba más atento. En el último de esos encuentros dijimos que nos tendríamos que juntar un fin de semana, pero ya para salir, ir a bailar, hacer algún plan de ese estilo. Quedamos finalmente para ese sábado en la casa de nuestro amigo.

Como el plan incluía cena, nuestro amigo pidió unas empanadas, preparó una picada y cada cual llevó algo para tomar, después dividiríamos gastos. Éramos cinco varones gais, comiendo, tomando y bailando, haciendo previa ${ }^{31}$ para ir a una fiesta. Durante la cena apareció la cuestión de las relaciones abiertas y los arreglos no monógamos. Claro que todos tenemos posiciones al respecto. Un amigo contaba que para él la monogamia era lo peor que existía. Otro tenía una visión más comprensiva, pues no le parecía adecuado ser tan tajante; él podría decir que a él no le había funcionado. Cuando tomé la palabra (además de un poco vino) quería decir algo sobre relaciones abiertas desde mi lugar como investigador del amor hasta que vi los brillosos ojos de Luchi. Ahí, en ese mismo momento, atemperé mi discurso y moderé lo que quería decir: "En el caso de las parejas que tienen relaciones no monógamas, por lo menos desde mis informantes, aparecen tales problemas". Salí bastante airoso de la situación (o al menos eso creo), sin decir que tales o cuales varones me contaron tal o cual cosa, sino valiéndome de mis datos y garantizando la no exposición de las historias íntimas y personalísimas de cada uno de los varones a los que había entrevistado, como era el caso de Luchi. 
Entender cómo podría ser comparado con aquella categoría requiere comprender de qué modo habían ido apareciendo las amistades en la relación que había tenido Luchi con su novio. Significa, también, entender cómo operaba esa red que contenía y daba forma a la pareja que se venía consolidando. Una de las veces en que Luchi me habló de sus amigos fue cuando me contó, en nuestro segundo encuentro, que su fin de semana había sido muy intenso a nivel emocional. Había pasado un viernes y parte del sábado de gloria, ya que se había encontrado con un chico que le interesaba y con el que venían pegando onda, es decir, teniendo afinidad. Pero la segunda mitad del sábado y el domingo fue de angustia: no solo se había dado cuenta de que se estaba empezando a enganchar más de lo que hubiera querido con ese pibe -al punto de estar pendiente de si le escribía o no-, sino también que había rechazado en el mismo fin de semana dos ofertas de su ex novio para juntarse a comer. Luego de escucharlo, le pregunté si había charlado con sus amigos al respecto y me respondió que había preferido no hacerlo. De hecho, muchas veces le costaba conversar con amigos sobre ciertas cosas íntimas, pues no tenía ganas de enfrentarse con los discursos moralistas que le podían ofrecer otras personas, a las que quiere y respeta, pero que no están en su lugar. Prefiere llegar a una conclusión personal y luego sí compartir sus pensamientos.

Una segunda vez que probó mi confianza fue cuando le pregunté, en nuestro tercer encuentro, por las fantasías sexuales y eróticas en su relación con su ex. Después de cierto rodeo y de contarme algunas cosas, llegó a explicarme una fantasía, algo que lo excitaba a él, por cosas que hacía su novio. Aunque a mí no me parecía ni tan raro ni tan tabú, entendí que para Luchi era algo muy privado, que solo supimos algunas personas. Lo que me diferenciaba del resto era que yo había tomado en serio sus palabras. No es que sus amigos desconfiaban de lo que él les decía, sino que lo juzgaban por creerle a su, en ese momento, novio. Mi posición fue la de tomar como verdad no solo lo que Luchi me contaba, sino también lo que él creía como verdadero, que era lo que su novio le había dicho.

Volviendo a la escena de la parada del colectivo, debo confesar que lo que me dijo sobre algo que había pasado con su ex me tomó por sorpresa, y esto complicó mi intento de acurrucarme en mi camisa para aliviar del frío. Pero ese comentario siguió en mi mente, y me mantuvo despierto en mi trayecto a casa (sirvió de hecho para que no me durmiera y siguiera de largo). Unos días me llevó entender que estaba llegando a un punto en el que, sin quererlo, para mis entrevistados ya estaba mudando mi ropa; no siempre era un investigador y analista externo sino que también, por momentos, se me asociaba con otras categorías. Estas categorías dependían tanto de la situación de interacción (como en este caso una salida con amigos) como de la vía de contacto (por medio de un amigo en común). Según Guber (2014), la reflexividad nos permite pensar la situación de construcción de conocimiento en el campo, que incluye además nuestro ingreso en este (o, como es mi caso, la forma en que contacto a los entrevistados).

Mate de por medio, nuestro último encuentro por la entrevista fue en su casa. Sentados en el balcón, bajo el atardecer de un día primaveral, charlamos sobre cómo habían ido apareciendo los amigos de Luchi y de su ex en su relación. Su poca timidez lo acercó a los amigos de su ex, cuando todavía eran novios. Muchas veces cenaban todos juntos, iban a bailar y hacían otro tipo de salidas. Él se llevaba muy bien con todos ellos. Se llevaba bien con ellos al punto de que cuando se separó de su ex, la última vez que comieron todos juntos, Luchi se sintió mal. Fue ahí cuando se dio cuenta de que ya no iba a seguir viendo, con la misma frecuencia, a los amigos de su ex, de quien se había hecho amigo, pero justamente por ser su novio. Mientras me daba un mate, su voz se notaba apenada, dado que volvía a confirmar que terminar la relación con su novio implicaba desanudar esa red que durante casi dos años habían ido tejiendo juntos. En esa red se insertaban los amigos de uno y del otro, los terceros, la familia y un sinfín de actantes más (humanos y no humanos, como objetos y cosas). Entre esos actantes, como vimos, podría haberme encontrado yo, de no haber sido porque nuestro contacto comenzó una vez que Luchi ya se había separado de su ex, aunque todavía seguían "pasando cosas". 


\section{Conclusión: LOS DE AFUERA NO SON SOMOS DE PALO}

A lo largo de estas páginas me propuse reflexionar sobre el lugar que ocupo como investigador de relaciones amorosas entre varones gais. Esto implica buscar con qué categorías fui interpelado en el campo, es decir, cómo fui pensado y con quiénes fui asociado por estos varones a los que vengo entrevistando. Como sostiene Zenobi (2010), esas categorías no son un mero dato anecdótico, sino que se inscriben dentro de las prácticas sociales que estudiamos, por lo que es necesario desplegar su historicidad. Estas categorías forman parte de las historias de amor que son objeto de análisis, de allí la centralidad que revista detenernos en ellas. De acuerdo con Guber (2014), un aspecto determinante de cómo nos toman las personas con quienes trabajamos se relaciona con el modo en que ingresamos al campo. Si bien considero que esa puerta de ingreso es fundamental para comprender, en clave de reflexividad, sobre qué aspectos nos pueden hablar, el modo en que nos categorizan no se congela en dicho acercamiento al fenómeno a estudiar. Por el contrario, a medida que va pasando el tiempo, el mismo ejercicio de investigación implica ciertos corrimientos que nos hacen pivotear en dichas categorías, como explica Zenobi (2010). En otras palabras, esto no implica que todo el tiempo haya sido visto como tal ni que por todos los entrevistados pueda ser caracterizado de la misma manera, sino que fui pivoteando desde mi rol de investigador hacia otras categorizaciones. Hacerlo lleva a hablar de mí como sujeto del conocimiento, pero también permite dar cuenta de que esas categorías con las que me asocian tienen sentidos específicos para estos varones en sus historias amorosas. Finalmente, la apuesta fue volver a estas historias desde un esquema de pareja que no restringiera la participación de otras personas (y cosas) en ese ensamblaje.

En consonancia con dicho objetivo, me concentré en las categorías principales con las que fui pensado a partir de cuatro situaciones puntuales. La primera de ellas fue la del levante. Para Juli, a quien contacté por medios virtuales, la investigación doctoral le pareció un chamuyo para intentar levantarlo. Esto reviste un cariz especial cuando se entiende que una vía de entrada privilegiada al mercado de intercambios eróticos o chongueo, como lo resumió otro informante, son los medios virtuales. De allí que ser visto como un intento de levante también permita ver cómo circula, se consume y se consuma el erotismo.

Si bien el novio de Juli me vio como una posible amenaza, quien lo pensó realmente así fue el novio de Patricio. Fui el tercero, que disparó una escena de celos por parte de su novio, que pensó que tantos encuentros implicaban algo más que una entrevista. Fui un tercero equiparable a otros que tuvieron historia, como el ex de Patricio y un amigo de su novio, con quien había pasado algo. Pensar cómo aparecen los terceros en las parejas nos permite observar otras pautas de sociabilidad entre gais, pautas que dan pista de la porosidad de ciertas categorías analíticas.

Desactivar esa escena de celos requirió que Patricio recurriera a una estrategia personal: el modo en el que habla. Esa manera de hablar fue una clave de esta entrevista, pero muy distinta a la estrategia discursiva de Marcos. Para él, nuestros encuentros por momentos se confundieron con las sesiones con su psicóloga. Ser equiparado a un terapeuta me llevó a rastrear tres -jugando con los términos de ese discurso- intervenciones. La primera refiere a los desplazamientos genéricos que se dan cuando se habla del amor en entrevistas: sobre eso se suele charlar en terapia. La terapia -segunda intervención- es una herramienta individualizante muy difundida en varones gais, practicada por casi la totalidad de entrevistados. Última intervención: mantener a salvo la confidencialidad para no poner en riesgo los secretos que me contaban y que no debían conocer sus novios.

Marcos me advirtió que no quería que entrevistara a su novio, básicamente porque me había contado cosas que sabían solo su terapeuta y sus amigos. Quien de a ratos me comparó con un amigo fue Luchi. Él, luego de nuestras entrevistas, me contó algo que sus amigos hasta ese momento no sabían, porque yo, a diferencia de esos amigos, no lo juzgaría. De eso no había dudas desde que me había confiado otras intimidades y no le di ningún discurso moralista al respecto, como sí habían hecho algunas de sus amistades. 
Haber rastreado cómo fui pensado por mis entrevistados implicó que iluminara otras cuestiones, sobre las que fui hablando al pasar en cada uno de los apartados. Pues, en última instancia, como investigador que forma parte del mundo que investiga, estas cosas no me son del todo ajenas. Y, de todos modos, el ejercicio de distanciamiento y reflexividad me lleva a recuperar aspectos del modo en que aman (¿amamos?) los varones gais, que se cristalizan en historias concretas.

Entre estos aspectos del amor realmente existente pretendo destacar cómo las parejas no deben ser reducidas a un vínculo de dos individuos completamente independientes. Por el contrario, reconstruir esa red de personas que forman parte de las parejas implica ver cómo intentos de levante, terceros en discordia comparables a ex, terapeutas y amistades ayudan a ensamblar (o desanudar) esas parejas. Otras personas de las que hablé al pasar fueron los familiares, también presentes en las historias de amor, aunque, por razones obvias - pues no entrevisté a ningún familiar mío-, no fui pensado como uno de ellos. El haber sido pensado, por momentos, a partir de dichas categorías propone un desafío a los estudios sociales del amor, que tienden a tomar por sentada a la individualidad, como un proyecto acabado. De este modo, la propuesta de ir viendo cómo aparecen esas otras personas a lo largo de las historias de amor implica volver a trazar los criterios a la hora de definir esos ensamblados que son las parejas. El carácter situacional del cómo fui pensando nos invita a dar cuenta de que esas otras personas se van reactualizando en el tiempo durante las trayectorias amorosas, por lo que, al igual que las estrellas que conforman las constelaciones, tienen una presencia titilante. En dicho carácter titilante, investigar ese amor de pareja me ha llevado, incluso sin quererlo, a verme involucrado en sus historias. Me ha llevado a entender, entonces, que los de afuera no somos de palo.

\section{Agradecimientos}

Agradezco los valiosos comentarios de María Lis Baiocchi, María Florencia Blanco Esmoris, Santiago Canevaro, Solange Godoy, Julián Ortega, Mariana Palumbo, Jesica Pereiro, Mariano Perelman y Verónica Santalla a una primera versión de este trabajo. Hago extensivo el agradecimiento a quienes evaluaron el texto, cuyas recomendaciones han contribuido enormemente a mejorar el escrito.

\section{Bibliografía}

Adam, J. M. y Heidmann, U. (2004). Des genres à la généricité. L'exemple des contes (Perrault et les Grimm). Langages, 38(153), 62-72.

Adamovsky, E., Visacovsky, S. E., y Vargas, P. (2014). Clases medias: Nuevos enfoques desde la sociologi\#a, la bistoria y la antropologi\#a. Buenos Aires: Ariel.

Agier, M. (2012). Pensar el sujeto, descentrar la antropología. Cuadernos de Antropología Social, 35(0), 9-27.

Araujo, K. y Martuccelli, D. (2010). La individuación y el trabajo de los individuos. Educação e Pesquisa, 36(0), 77-91.

Bajtín, M. (1982). El problema de los géneros discursivos. En Estética de la creación verbal (pp. 248-293). México: Siglo XXI.

Bazin, J. (2017). Interpretar o describir. Notas críticas sobre el conocimiento antropológico. En M. Garzón Rogé (Ed.), Historia pragmática. Una perspectiva sobre la acción, el contexto y las fuentes (pp. 105-124). Buenos Aires: Prometeo Libros.

Beck, U., y Beck-Gernsheim, E. (2001). El normal caos del amor. Las nuevas formas de la relación amorosa. Barcelona: Paidós.

Boltanski, L. (2000). El amor y la justicia como competencias. Buenos Aires: Amorrortu.

Boy, M. (2008). Significaciones y uso del espacio virtual en hombres gays de Buenos Aires. En M. Pecheny, C. Fígari y D. Jones (Comps.), Todo sexo es politico. Estudios sobre sexualidades en Argentina (pp. 73-94). Buenos Aires: Libros del Zorzal. 
Braz, C. (2010). À meia-luz... Uma etnografia imprópria em clubes de sexo masculinos (Tesis de Doctorado). Programa de Doutorado em Ciências Sociais, Instituto de Filosofia e Ciências Humanas da Universidade Estadual de Campinas, Brasil.

Corrales, J. (2010). The LGBT Organizational Density of World Cities. En J. Corrales y M. Pecheny (Eds.), The Politics of Sexuality in Latin America. A reader on Lesbian, Gay, Bisexual and Transgender rights (pp. 372-378). Pittsburg: University of Pittsburg Press.

Daskal, R., y Garriga Zucal, J. (2015). Elias en La 12. Una aproximación eliasiana a la violencia en el fútbol en la Argentina. Revista del Museo de Antropología, 8(2), 187-192

Elias, N. (1996 [1969]). La sociedad cortesana. México: Fondo de Cultura Económica.

Elias, N. (2008 [1970]). Sociología fundamental. Barcelona: Gedisa.

Fasano, P. (2006). De boca en boca. El chisme en la trama social de la pobreza. Buenos Aires: Antropofagia.

Foote Whyte, W. (1971). La sociedad de las esquinas. México: Editorial Diana.

Gallego Montes, G. (2010). Demografia de lo otro. Biografias sexuales y trayectorias de emparejamiento entre varones en la Ciudad de México. México: El Colegio de México.

García Andrade, A., y Sabido Ramos, O. (2014). Cuerpo y afectividad en la sociedad ontemporánea. En A. García Andrade y O. Sabido Ramos (Coord.), Cuerpo y afectividad en la sociedad contemporánea (pp. 11-35). México: Universidad Autónoma Metropolitana.

Garriga Zucal, J. (2005). 'Haciendo amigos a las piñas'. Interacciones, intercambios y relaciones de una hinchada de fútbol. [Exclusivo en línea]. EFDeportes.com, 10(88). Recuperado de https://www.efdeportes.com/efd88/hinc hada.htm

Giddens, A. (2004). La transformación de la intimidad. Sexualidad, amor y erotismo en las sociedades modernas. Madrid: Cátedra Teorema.

Guber, R. (2004). El salvaje metropolitano. Reconstrucción del conocimiento social en el trabajo de campo. Buenos Aires: Paidós.

Guber, R. (2011). La etnografía: método, campo y reflexividad. Buenos Aires: Siglo XXI.

Guber, R. (2014). Introducción. En R. Guber (Comp.), Prácticas etnográficas. Ejercicios de reflexividad de antropólogas de campo (pp. 13-40). Buenos Aires: Miño y Dávila.

Hakim, C. (2012). Capital erótico: el poder de fascinar a los demás. Buenos Aires: Debate.

Heredia, M. (2011). Ricos estructurales y nuevos ricos en Buenos Aires: primeras pistas sobre la producción y la recomposición de las clases altas. Estudios Sociológicos, 29(85), 61-97.

Illouz, E. (2009). El consumo de la utopía romántica. El amor y las contradicciones culturales del capitalismo. Buenos Aires: Katz.

Illouz, E. (2010). La salvación del alma moderna. Terapia, emociones y la cultura de la autoayuda. Buenos Aires: Katz.

Illouz, E. (2012): Por qué duele el amor. Una explicación sociológica. Buenos Aires: Katz/Capital Intelectual.

Jónasdóttir, A. G. (2014). Los estudios acerca del amor: un renovado campo de interés para el conocimiento. En A. García Andrade y O. Sabido Ramos (Coord.), Cuerpo y afectividad en la sociedad contemporánea (pp. 39-80). México: Universidad Autónoma Metropolitana.

Latour, B. (2007). Nunca fuimos modernos. Ensayo de antropología simétrica. Buenos Aires: Siglo XXI.

Latour, B. (2008). Reensamblar lo social: una introducción a la teoría del actor-red. Buenos Aires: Manantial.

Leal Guerrero, S. (2011). La Pampa y el Chat. Aphrodisia, imagen e identidad entre hombres de Buenos Aires que se buscan y encuentran mediante internet. Buenos Aires: Antropofagia.

Lomnitz, L. (1975). Cómo sobreviven los marginados. México: Siglo XXI.

Luhmann, N. (2008). El amor como pasión. La codificación de la intimidad. Barcelona: Península.

Marentes, M. (2017a). Amor entre varones gays. Un análisis de producción cultural a partir del matrimonio igualitario (2010) en la Argentina (Tesis de maestría). Universidad Nacional de General San Martín, Buenos Aires, Argentina. 
Marentes, M. (2017b). Escenas de espera en amor gay. En Mario Pecheny y Mariana Palumbo (Comps.), Esperar y hacer esperar: escenas y experiencias en salud, dinero y amor (pp. 247-277). Buenos Aires: Teseo Press.

Marentes, M. (2017c). Corporalidades velcradas: la construcción de ethos discursivos en salones de chat gays. Revista Latinoamericana De Estudios Sobre Cuerpos, Emociones Y Sociedad, 0(24), 25-36.

Marentes, M. (2019). Jugando al amor. Actualizaciones temporales en un juego de una pareja gay. Lúdicamente, 8(15), $1-13$.

Meccia, E. (2006). La cuestión gay. Un enfoque sociológico. Buenos Aires: Gran Aldea Editores.

Meccia, E. (2011). Los últimos homosexuales. Sociología de la homosexualidad y la gaycidad. Buenos Aires: Gran Aldea Editores.

Nardacchione, G. (2011). El conocimiento científico y el saber práctico en la sociología pragmática francesa. Apuntes de Investigación del CECYP, 14(19), 171-182

Olcón-Kubicka, M. (2016). Financial Arrangement as a Reflection of Household Order. Polish Sociological Review, 4(196), 477-494.

Ortega, J. (2017). Sexualidades disidentes en el trabajo. Sociabilidad de gays y lesbianas en el sector de enfermería. Buenos Aires: Universidad de Buenos Aires. Tesis de maestría.

Piovani, J. I., y Muñiz Terra, L. (Comps.) (2018). ¿Condenados a la reflexividad? Apuntes para repensar el proceso de investigación social. Buenos Aires: CLACSO-Biblos.

Salessi, J. (1995). Médicos, maleantes y maricas. Higiene, criminología y homosexualidad en la construcción de la nación Argentina. (Buenos Aires: 1871-1914). Rosario: Beatriz Viterbo Editora.

Semán, P. (2006). Bajo continuo: exploraciones descentradas sobre cultura popular y masiva. Buenos Aires: Gorla.

Sívori, H. (2004). Locas, chongos y gays. Sociabilidad homosexual masculina durante la década de 1990. Buenos Aires: Antropofagia.

Swidler, A. (2001). Talk of love. How Culture Matters. Chicago: The University of Chicago Press.

Zenobi, D. (2010). O antropólogo como 'espião': das acusações públicas à construção das perspectivas nativas. Mana, 16(2), 471-499.

\section{Notas}

1 La denominación correcta de la capital del país es Ciudad Autónoma de Buenos Aires. Por intentar respetar la forma en que los entrevistados denominan a este distrito, se apela a su antiguo nombre: Capital Federal o simplemente Capital. El Gran Buenos Aires corresponde a un conjunto de 24 partidos de la Provincia de Buenos Aires, que próximos a la capital del país, conforman el Área Metropolitana de Buenos Aires, la zona urbana más poblada del país donde reside casi un tercio de la población. El criterio de elección de esta área en donde conducir la investigación responde a que en ella se consolidó un fuerte nodo de espacios de diversidad sexual (Meccia, 2006, 2011), como al hecho de que la Ciudad de Buenos Aires es una reconocida capital internacional de diversidad sexual (Corrales, 2010).

2 El criterio etario se corresponde con la propuesta de Meccia (2011), quien postula que los varones gais jóvenes fueron socializados bajo un régimen sociosexual en el que la diversidad sexual ha sido más tolerada, con respecto a décadas previas. En este contexto aumentaron las posibilidades de establecer relaciones amorosas con otros varones a partir de la mayor aceptación social.

3 Este criterio difiere, por ejemplo, del seguido por Gallego Montes (2010), quien, para estudiar demográficamente el amor gay, establece un límite temporal: relaciones de más de tres meses.

4 Para un ejemplo del debate en antropología entre las categorías de sujeto, individuo y persona, véase Agier (2012)

5 En antropología existe una amplia trayectoria de trabajos que no hacen sino mostrar que los sujetos no son simplemente individuos, sino que se definen en sus relaciones. Por citar solo algunos trabajos (Daskal y Garriga Zucal, 2015; Fasano, 2006; Foote Whyte, 1971; Garriga Zucal, 2005; Lomnitz, 1975; Semán, 2006; Sívori, 2004).

6 Esta expresión intenta resumir que las demás personas que exceden a una interacción no tienen derecho a opinar. Claro que su uso no se limita al ámbito de las parejas, de hecho también es muy recordada por un partido de fútbol. Como intento mostrar en estas páginas, siempre las parejas son "mucho más que dos", por lo que los de afuera no son tan de palo.

7 El accidente refiere al incendio de un boliche bailable, República de Cromañón, situado en la Ciudad de Buenos Aires, que tuvo lugar el 30 de diciembre de 2004. Como resultado de dicho incendio, murieron 194 personas. 
8 Se trata de no de los barrios en que se divide la Ciudad de Buenos Aires y que desde los años noventa sufrió un importante proceso de gentrificación. Este barrio, ubicado en la zona centro-norte de la ciudad, es un nodo central de espacios de sociabilidad y encuentro, y un importante punto turístico. En Palermo abunda la oferta de locales comerciales destinados a un público gay.

9 Quiere decir que había buscado mi nombre y apellido en la web. Usualmente se utiliza stalkear como forma coloquial de espiar a una persona. Stalkear es un neologismo, que se convierte en un verbo, y deriva del término inglés stalker, que significa acosador o acosadora.

10 Chamuyo define a un discurso poco certero y exagerado, que habitualmente se utiliza con el fin de seducir a alguien. De todos modos, chamuyar trasciende el ámbito de la conquista y puede referir a decir mentiras o exagerar.

11 Habitualmente se asocia a la zona norte de la Ciudad de Buenos Aires y del Gran Buenos Aires con las clases más acomodadas, mientras que el nivel socioecononómico va descendiendo hacia zona sur. Con todo, estos ordenamientos socioterritoriales no son del todo precisos, pero siguen operando como imaginarios estructurantes de la distribución socioespacial de la población del Área Metropolitana de Buenos Aires (Heredia, 2011).

12 Feriado nacional por el Día Nacional de la Memoria por la Verdad y la Justicia, en la que se conmemora la última y más sangrienta dictadura cívico-militar de Argentina, que comenzó con el derrocamiento de la entonces presidenta María Estela Martínez de Perón, el 24 de marzo de 1976.

13 La zona de Plaza Italia, en el corazón de Palermo, es un nodo de transporte muy importante, donde convergen estaciones de metro, de trenes y colectivos. Este punto geográfico es un punto de referencia para Juli. Ahí mismo tomé un colectivo que realizaba un servicio directo entre Plaza Italia y la localidad en donde vive, tal como me indicó Juli, una de las veces en que fui para su casa.

14 Para ver diferentes formas de lidiar con la situación, véase Braz (2010) y Leal Guerrero (2011).

15 Urbanización privada que se ubica en el partido de Tigre, compuesta por una serie de barrios privados y countries sumamente exclusivos.

16 Forma coloquial de decir que alguien es atractivo.

17 Es decir, un pacto de no monogamia en que estaba permitido tener encuentros sexuales con otros varones

18 Chongo es una categoría habitual en la jerga homosexual argentina. Según Rapisardi y Modarelli (2001), que retoman de Salessi (1995), se utilizaba desde principios del siglo veinte para referir a aquellos varones "heterosexuales" que penetraban a los varones "homosexuales". Sívori (2004) ofrece un análisis de esta categoría dentro del habla de las locas, el argot gay rosarino de los años noventa, detectando la imposibilidad de autodefinirse como tal: pues un chongo, que sería heterosexual, no utilizaría este concepto para referirse a sí mismo, ya que sería indicador de compartir aquel código discursivo y dejaría de ser tan chongo. Actualmente, este término dejó de ser exclusivo del ambiente gay, y ya chongo refiere a un varón con quien se tiene sexo, aunque la relación no implique necesariamente un compromiso afectivo mayor. En el último tiempo, comenzó a utilizarse en femenino (chonga) para referir una compañera sexual casual.

19 Estos jóvenes, al momento de las entrevistas con Patricio, continuaban viviendo con sus padres. Estaban ahorrando para, en un futuro cercano y luego de que regresaran de un viaje a Europa que harían en abril de 2018, emprenderse en la convivencia. Debido a la duración de la carrera de Lean — como estudiante de medicina - se fue dilatando aquel ansiado proyecto, hasta que este, ahora médico, comenzara a trabajar haciendo la residencia para la especialización en ginecología y obstetricia.

20 Amigarche combina la amistad con la práctica sexual. Un término similar sería amigos con derechos. Este término no es exclusivo del ambiente gay argentino.

21 Distraído, olvidadizo, despistado.

22 De segunda categoría, de menor jerarquía.

23 En referencia a la canción "Desde lejos no se ve", de la banda de rock nacional argentino Los Piojos (1998).

24 Provocativamente llamo a estos encuentros sesiones, por cómo Marcos me comparó momentáneamente con un terapeuta.

25 El trabajo de Swidler (2000) muestra cómo también otros saberes expertos son consultados para hablar sobre el amor, como consultores matrimoniales y referentes religiosos.

26 Como me hizo notar Julián Ortega, tal vez el hecho de que varones gais hagan o hayan hecho terapia se relacione con su sexualidad. Al menos en el caso de los varones a los que entrevisto, algunos llegaron por eso, mientras que otros por una variedad de temáticas.

27 Efectivamente podría asociarse este fenómeno con la extendida literatura sobre trabajadores de cuello rosa y sobre inserciones laborales de varones gais (Ortega, 2017). En este trabajo solamente lo sugiero, pues hasta el momento no he sistematizado los patrones y trayectorias de clases de los entrevistados en sus carreras laborales, tarea que pretendo realizar en un futuro cercano.

28 El proyecto de investigación tuvo una evaluación ética, además de las recurrentes reflexiones en torno a estas cuestiones, que fueron discutidas con mis directores. Entre las disposiciones éticas, se incluye no solo el consentimiento oral de los entrevistados sino también uno escrito. 
29 Discoteca, local bailable.

30 Es decir, que no fueron grabadas.

31 La previa implica juntarse con gente, por lo general en casas particulares, para conversar y tomar algo antes de salir a bailar a una discoteca. 